\title{
PSYCHE
}

Vol. 95

1988

No. 3-4

\section{CHEMICAL COMMUNICATION IN MERANOPLUS (HYMENOPTERA: FORMICIDAE)*}

\author{
BY BERT HÖLLDOBLER \\ Department of Organismic and Evolutionary Biology \\ Harvard University \\ Cambridge, Mass. 02138, U.S.A.
}

\begin{abstract}
INTRODUCTION
The chemical communication systems of social insects, and in particular of ants, has been intensively studied by many research groups during the past 25 years. These studies included the identification and description of exocrine glands involved in pheromone production (see Hölldobler and Engel, 1978; Hölldobler, 1982; Jessen et al 1979; Billen, 1987), the investigation of the natural product chemistry of pheromones (see Blum, 1982; Morgan, 1984; Attygalle and Morgan, 1985), and the study of the underlying behavioral mechanisms and evolution of chemical communication (see Hölldobler, 1978; 1984; Buschinger and Maschwitz, 1984). Nevertheless, there are some groups of ants that have been almost completely neglected by behavioral biologists in spite of the fact that they are relatively abundant and probably ecologically important. One such group is the genus Meranoplus, which is very common in Australia. In this paper I report the results of my experimental studies of the communication behavior of several Australian Meranoplus species.
\end{abstract}

${ }^{*}$ Manuscript received by the editor October 27, 1988. 


\section{Material AND Methods}

The work was conducted in the laboratories of the Division of Entomology of CSIRO in Canberra, Australia, during a research year in 1980. Colonies of Meranoplus were collected near Canberra (ACT), near Poochera, South Australia, and near Lake Eacham and Eungella, Queensland. A total of seven species were investigated. They are listed in table 1 with my acquisition number and the species number of the Australian National Insect Collection (ANIC)/ (assigned by R. W. Taylor), where voucher specimens have been deposited.

Colonies or groups of workers with brood have been housed in moist gypsum nests, or in test tubes containing water held in by a cotton plug, and fed honeywater, freshly killed cockroaches and a specially prepared diet (Bhatkar and Whitcomb, 1970). The nest of each colony was placed in plastic boxes $(30 \times 75 \times 10 \mathrm{~cm})$ which served as foraging arenas.

Glandular dissections were performed in distilled water on ants killed by placing them for a few minutes in a freezer. Additional information concerning procedures will be given with the description of the individual experiments.

\section{RESULTS}

\section{Recruitment to nests and food}

The most detailed results were obtained with Meranoplus sp. no. 11. Two colonies of this species were collected in the Corin Dam area, near Canberra. Each of the colonies had one queen, approximately 200 workers and larvae. In addition, in the same area, I collected two queenless worker groups each containing approxi-

Table 1. Species of Meranoplus investigated in this study.

\begin{tabular}{lccl}
\hline Species & $\begin{array}{c}\text { Acquisition } \\
\text { number }\end{array}$ & $\begin{array}{c}\text { ANIC } \\
\text { number }\end{array}$ & Locality \\
\hline Meranoplus hirsutus & 135 & & Near Lake Eacham, Qld \\
& 177 & & Eungella, Qld \\
Meranoplus sp. & 32 & 11 & Near Canberra, ACT \\
Meranoplus sp. & 70 & 11 & Near Canberra, ACT \\
Meranoplus sp. & 150 & 12 & Near Monga Forest, NSW \\
Meranoplus sp. & 194 & 13 & Near Poochera, SA \\
Meranoplus sp. & 195 & 14 & Near Poochera, SA \\
Meranoplus sp. & 246 & 15 & Near Canberra, ACT \\
\hline
\end{tabular}


mately 50-60 workers. Although the queenless worker groups were found at least $50 \mathrm{~m}$ away from both queenright colonies, when they wer joined with a queenright colony, they readily merged without any sign of aggression or aversion.

The first indication that Meranoplus communicates by chemical trails was obtained when I dumped a field-collected colony inside the arena where I also provided a dark, moist test-tube nest. The colony first gathered in clusters along the arena wall. A few workers explored the surroundings of the arena, until after 43 minutes the first scout discovered the test tube nest. A few minutes later 3 more workers entered the nest. When leaving the nest the workers clearly exhibited trailing behavior, tapping their gaster tips repeatedly to the gound and sometimes even dragging them on the floor for distances of $0.5-1.0 \mathrm{~cm}$ (Fig. 1). This behavior was especially conspicuous near the entrance of the nest tube. Subsequently, the number of workers moving toward the nest increased markedly, although no clear trail following could yet be noticed. However, after an additional period of approximately 30 minutes, a continuous trail, leading from the cluster of ants to the nest, began to be established (Fig. 2a). Scouts, which returned from the newly discovered dark nest,

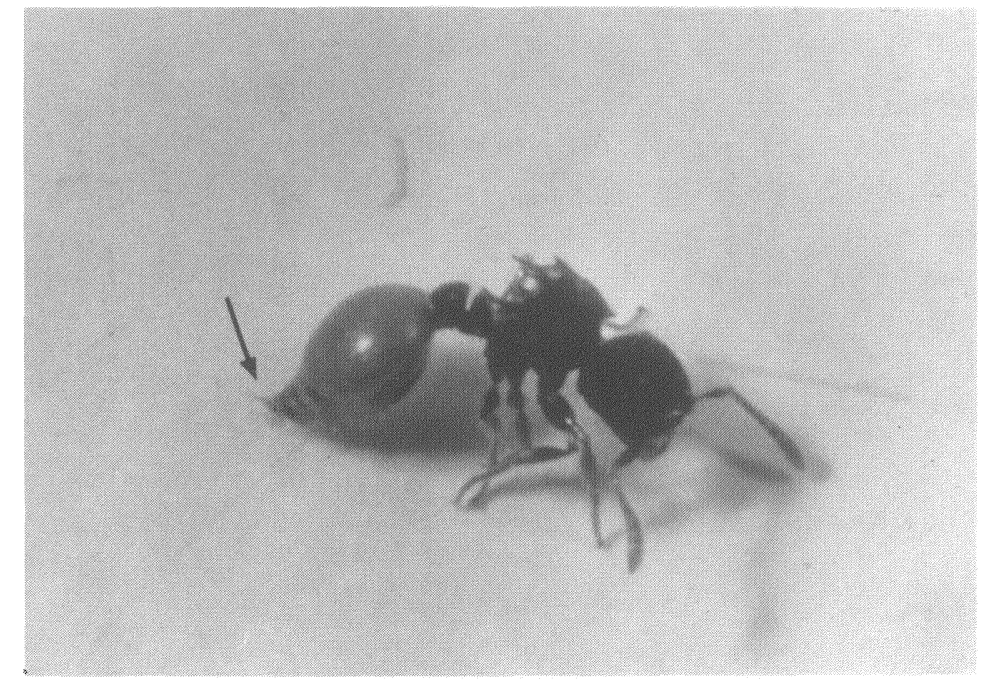

Figure 1. A worker of Meranoplus hirsutus dragging its abdominal tip over the ground during trail marking. The arrow points to the extruded sting. 
often exhibited a vigorous shaking behavior when encountering nestmates. This seemed to stimulate the nest mate to follow the trail. The shaking behavior was especially strong and persistent when recruiting workers encountered the queen. Often 3 to 6 workers approached the queen simultaneously, alternately gnawing with their mandibles on her cuticle or vigorously shaking their bodies toward the queen. This behavior was primarily aimed at the queen's gaster as if the workers were attempting to push the queen forward. At the beginning the queen moved very haphazardly, but once she contacted the trail, she walked straight to the nest. There was no pulling or dragging behavior, but occasionally I observed adult transport in the typical myrmicine mode, with the carried ant curled over the back of the carrier. The carried ant assumes the "pupal" position, with antennae and legs tightly folded to the body. Meranoplus workers often take this same position when mechanically disturbed. In addition I have seen them inside the nest in this position, lying on their sides as if they were sleeping.

Once the colony had settled inside the new nest I replaced the paper cover of the arena floor and offered honey water in the arena in approximately $15 \mathrm{~cm}$ distance from the nest entrance. As soon as the first forager discovered the food source it imbibed the liquid and returned to the nest. In order to observe the colony inside the nest I removed the aluminum foil cover from the nest tube. The ants did not show any sign of disturbance. The returning scout exhibited a vigorous shaking behavior when encountering nestmates. This behavior did not noticeably differ from that performed during colony movement. The scout engaged in frequent oral trophallactic exchanges, sometimes with 2 to 3 nestmates simultaneously. This behavior was frequently interrupted by renewed shaking behavior. When the scout finally left the nest again to return to the food source, it repeatedly dragged its abdominal tip on the ground for short intervals. The scout was usually followed by 5-15 ants (Fig. $2 b)$. When encountering nestmates in the arena, the scout also displayed the shaking which clearly appeared to stimulate the nestmates to follow along the trail to the food source. Occasionally I even observed recruiters moving repeatedly back and forth on the trail without even entering the nest, vigorously shaking their bodies whenever they encountered nestmates. This behavior resulted in a relatively quick establishment of a trail between food source and 


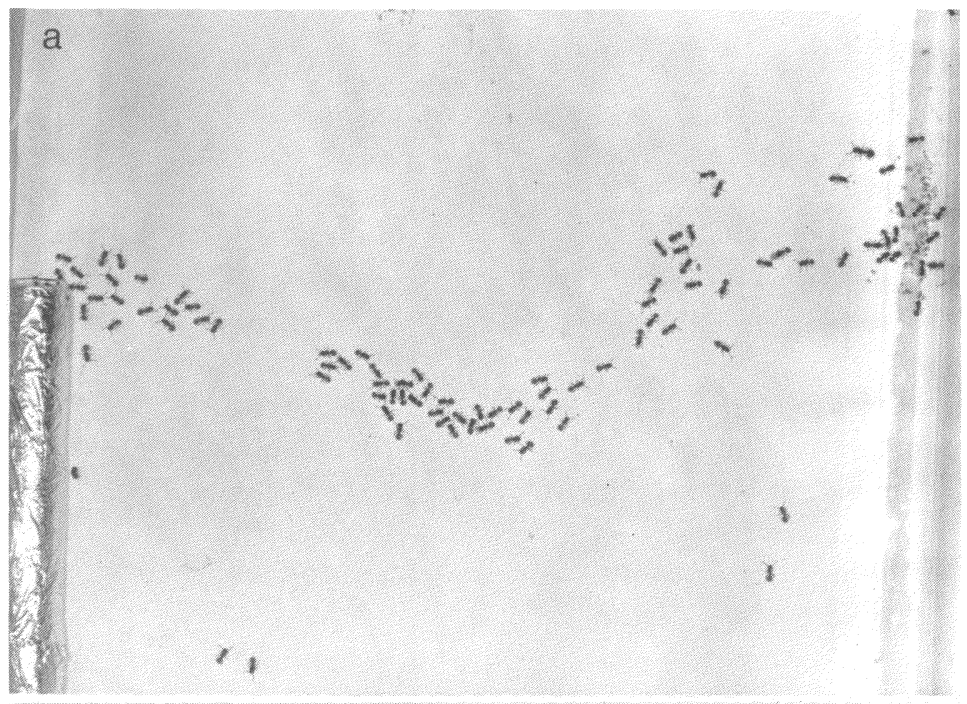

b
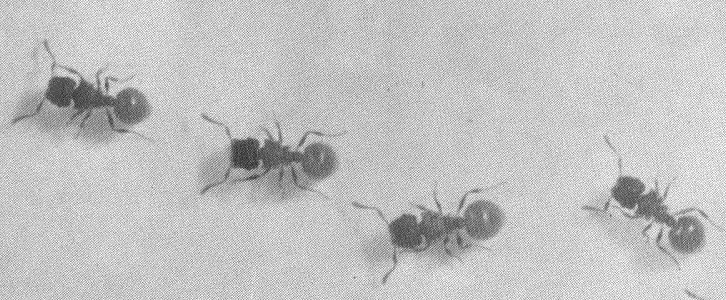

Figure 2. Trail following behavior in Meranoplus. a. During colony movements the ants move along a well established route to the nest provided in the test tube (covered with an aluminum foil). b. A trail laying recruiter moves from the nest to the food source and is followed by 6 nestmates. 
nest, because in this initial phase almost each worker returning from the feeding site to the nest appeared to lay a trail.

\section{The anatomical sources of the trail pheromones}

The fact that recruiting Meranoplus workers frequently tap with their abdominal tip the ground, suggests that either one of the major sting glands (Poison gland and/or Dufour's gland) or the rectal bladder are involved in trail communication. Each of the three organs were dissected out of freshly killed workers, crushed on hardwood applicators and rubbed along a line of $25 \mathrm{~cm}$ length. Each test trail was offered to the ants simultaneously with a control trail, which consisted either of water, or of the secretions of one of the other organs. Both trails originated in the same circle of $0.5 \mathrm{~cm}$ in diameter directly at the nest entrance, but diverged in an angle of $40^{\circ}$. The sides of control and test trails were changed in irregular sequence.

All Meranoplus species investigated have unusually large Dufour's glands. In the species Meranoplus sp. 11 the Dufour's gland stretches almost the whole length of the gaster, whereas the poison gland is relatively small, with a pair of bulging glandular filaments (Fig. 3). In a series of pilot tests it quickly became apparent that secretions from both the poison and Dufour's glands elicit trail following behavior in Meranoplus workers, whereas the contents of the rectal bladder had no effect as a trail substance. There was, however, a significant difference between the ants' responses toward the two trail substances: Trails drawn with crushed poison glands elicited a much stronger initial response than those drawn with Dufour's glands. The poison gland trails, however, were only effective for a few minutes, whereas Dufour's gland trails had an orienting effect for at least 7 hours and possibly even longer. Table 2 shows the quantitative results of the trail tests. It is interesting to note that considerably more ants followed the Dufour's gland trail when it was presented simultaneously with a poison gland trail, probably due to the stimulating effect of the poison gland secretions (independent samples t-test: $p=0.067$ ). This is further supported by the following results.

Dufour's gland secretions alone did not elicit a substantial trail following response in Meranoplus workers. But when a crushed poison gland on the tip of an applicator stick was offered simultaneously at the nest entrance, a significant number of ants emerged 


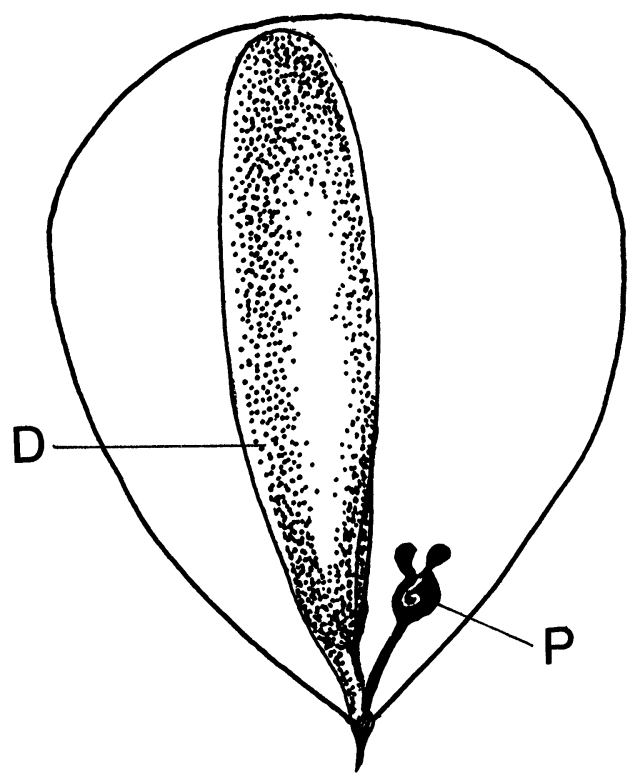

Figure 3. Schematical illustration of the outline of the gaster of a Meranoplus worker showing the large Dufour's gland (D) and the poison gland (P) with its bulging filaments.

from the nest and followed the Dufour's gland trail. From these experiments one can conclude that both the poison and the Dufour's gland serve in chemical trail communication. The poison gland secretions appear to function as relatively short lived recruitment signals. The Dufour's gland secretions do not elicit a strong recruitment response, but they appear to be much longer lasting, and motivated ants follow a Dufour's gland trail. This conclusion was further supported by the following experiments:

Meranoplus workers were stimulated to leave the nest along a 5 $\mathrm{cm}$ long trail drawn with a freshly crushed poison gland. After $5 \mathrm{~cm}$ this trail was continued with a trail drawn 60 minutes previously with Dufour's gland secretions. Almost $83 \%$ (24) of the ants arriving at the transition point continued to follow the Dufour's gland trail through at least $10 \mathrm{~cm}$. Additional observations in the laboratory and in the field confirm that Meranoplus establish trails which are very long lasting so that they function as trunk routes. From my 
Table 2. Number of workers of Meranoplus sp. no. 11 following artificial trails drawn with crushed poison and Dufour's glands. All ants following the trail at least through $10 \mathrm{~cm}$ during a 2 minute observation period were counted. The means and standard deviations of a total of 6 experiments for each combination are given.

\begin{tabular}{lclcll}
\hline Poison gland vs water & \multicolumn{2}{l}{ Dufour's gland vs water } & \multicolumn{2}{l}{ Poison gland vs Dufour's gland } \\
\hline $26.17 \pm 8.80$ & 0 & $4.17 \pm 1.72$ & 0 & $24.00 \pm 6.13$ & $8.33+4.32$ \\
\hline
\end{tabular}

experimental results I conclude that these long lasting routes are marked with Dufour's gland secretions.

Finally, I could not find evidence that the trail pheromones of Meranoplus are species specific. Meranoplus sp. no. 11 readily responded to poison gland trails of Meranoplus hirsutus. When glandular secretions of both species were offered simultaneosuly in a choice test, there was no preference for the conspecific poison or Dufour's gland trails. Meranoplus sp. no. 11 followed the poison gland and Dufour's gland trails of Meranoplus spp. no. 12, 13, 14, and 15. Similarly, Meranoplus sp. no. 14 followed trails drawn with poison or Dufour's gland secretions of M. hirsutus, M. spp no. 11 and 14.

Repellent secretions in the Dufour's glands

Most Meranoplus species studied became motionless and assumed a pupal position when they were mechanically disturbed. In contrast, $M$. hirsutus workers arched their gasters upright and extruded a whitish, sticky substance at the tip of the exposed sting (Fig. 4a). The same defense behavior could be observed when $M$. hirsutus foragers encountered other ant species, especially at a food source (Fig. 4b). The secretions, which originate from the Dufour's gland, elicit a strong repellent effect in other ant species such as Camponotus consobrinus, Polyrhachis sp. and Rhytidoponera sp. I was unable to test whether the Dufour's gland secretions of the other Meranoplus species studied have a similar defensive function in interspecific interactions.

\section{Nest site marking}

In the laboratory nests of Meranoplus sp. no. 11 I noticed that within a few days the paper floor of the foraging arena was marked with fecal droplets. These markings increased in density near the nest and were especially conspicuous directly at the nest entrance (Fig. 5a). 


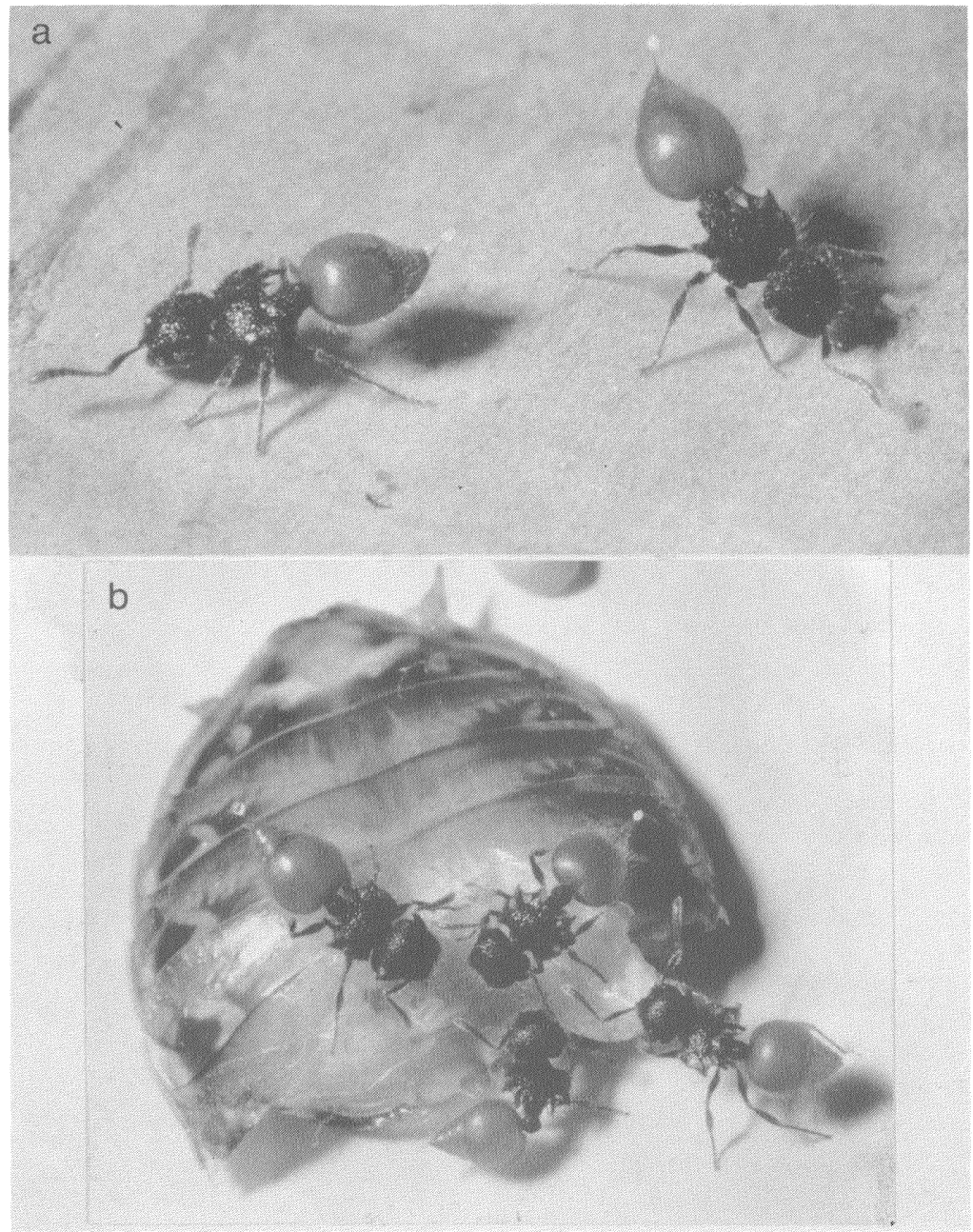

Figure 4. Meranoplus hirsutus workers in defensive posture. a. Workers which were mechanically disturbed, immediately arch up their gaster and extrude a droplet of Dufour's gland secretions on the exposed sting. b. The same behavior can be observed in workers guarding a piece of prey. 

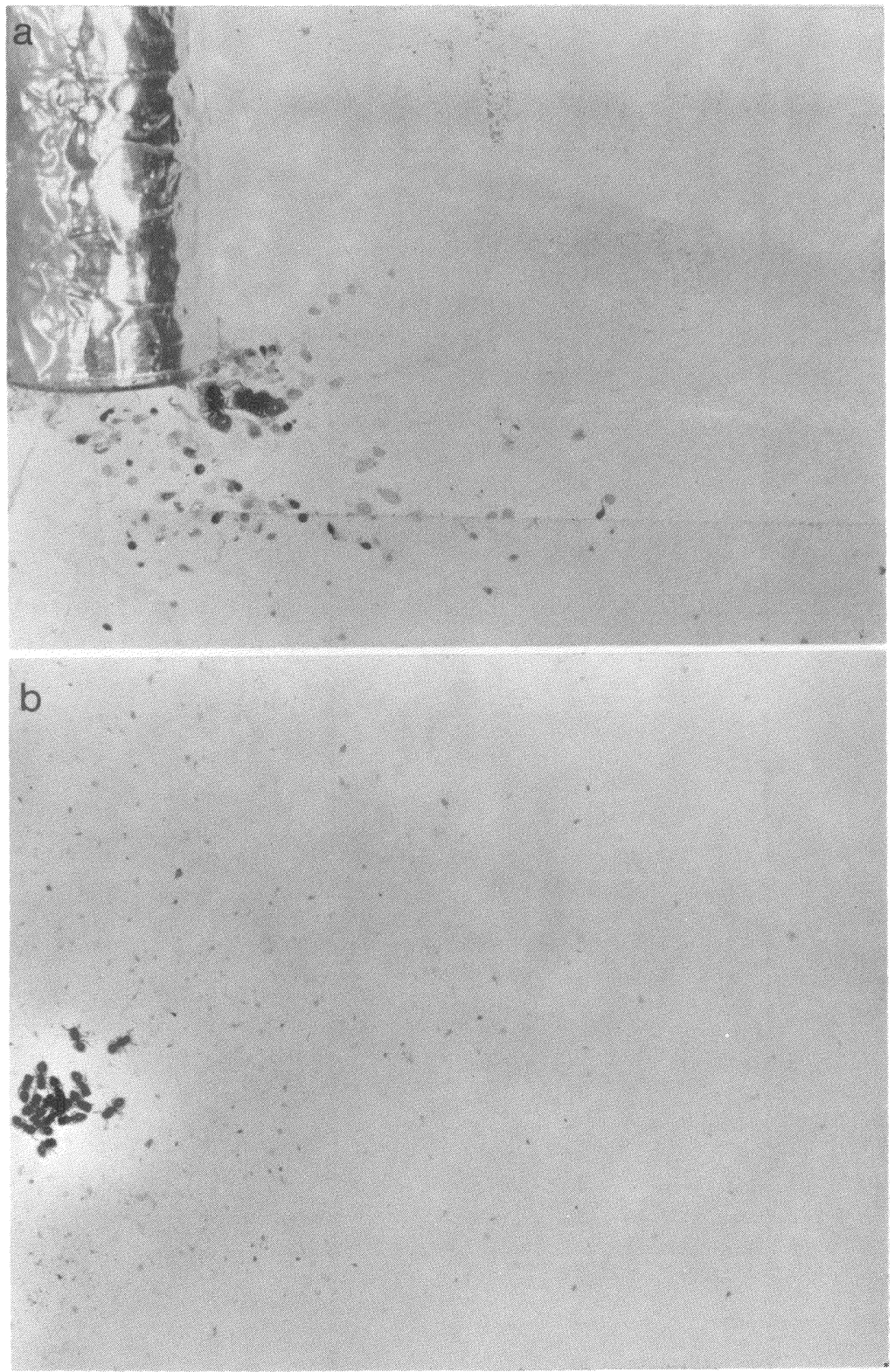

Figure 5. Nest area making in Meranoplus. a. The fecal spots are especially dense near the nest entrance. b. On a marked paper the Meranoplus workers gather directly at the spot where the nest entrance of a previously removed nest was located. 
To investigate whether these markings can serve as homing cues, the paper floor was placed into another arena and 20 ants, taken from the nest tube, were released in the new arena. In all five replicas of the same test, most of the displaced ants had gathered within 15 minutes at the exact spot on the paper floor where the nest entrance was previously located (Fig. 5b).

In a second series of tests the colony Meranoplus sp. no. 11 was transferred into a new arena with a new paper floor and two pieces of paper $(5 \times 5 \mathrm{~cm})$ were placed approximately $5 \mathrm{~cm}$ from the nest entrance. The centers of both papers were approximately $10 \mathrm{~cm}$ apart. Papers marked by the test colony, by a conspecific foreign colony, by a colony of another Meranoplus species and unmarked papers were tested in different combinations (Tab. 3). Approximately 40 ants were released into the arena, and subsequently the nest tube was removed. After an adjustment period of 15 to 20 minutes, I counted the number of ants on each paper. At least one hour elapsed before another test was conducted and the left-right arrangement of the pairs of test papers was alternated from test to test to take into account possible artifactual preferences for one side or another. As can be seen from table 3 workers of Meranoplus sp. no. 11 appear to be able to differentiate the markings from their own colony from those of conspecific foreign colonies and colonies of other Meranoplus species. Interestingly, when encountering foreign markings the ants did not exhibit a particular aggressive behavior or avoidance. This suggests that the markings do not function as territorial signposts, but rather as homing and colony recognition cues.

Table 3. Number of ants of the test colony (Meranoplus sp. no. 11) counted on papers marked by different Meranoplus colonies. The means of 7 experiments and standard deviations are given.

Test colony vs unmarked paper

$6.57 \pm 2.51 \quad 0.71 \pm 0.95$

Test colony vs foreign conspecific colony

$9.00 \pm 2.94 \quad 1.43 \pm 1.27$

Test colony vs colony of Meranoplus hirsutus

$8.14 \pm 3.72$

$1.43 \pm 2.15$ 


\section{SUMMARY}

The communication behavior of seven Australian species of the genus Meranoplus was studied in the laboratory. All species exhibited basically the same recruitment communication during nest movements and recruitment to food sources. Scouts stimulate nestmates by a vigorous body shaking behavior. They lay short lasting recruitment trails with secretions from the poison gland. Long lasting trunk routes are apparently marked with relatively non-volatile secretions from the Dufour's glands. All Meranoplus species studied have very large Dufour's glands, stretching the whole length of the gaster. In comparison the poison gland is small. In at least one species the secretions of the Dufour's gland also function as defensive secretions against enemies and predators. The nest area of Meranoplus is marked with colony specific chemical cues, which are probably contained in the fecal droplets.

\section{ACKNOWLEDGMENTS}

Many thanks to N. F. Carlin, who read the manuscript, and to R. W. Taylor for identifying the ants. I am most grateful to R. W. Taylor and the Division of Entomology, CSIRO, Canberra (Australia) for their generous hospitality. This work was supported by grants from the National Science Foundation, the National Geographic Society and a fellowship from the John Simon Guggenheim Foundation.

\section{REFERENCES}

Attygalle, A. B. And E. D. Morgan. 1985. Ant trail pheromones. Advances in Insect Physiology, 18: 1-30.

Billen, J. 1987. Morphology and ultrastructure of exocrine glands in social Hymenoptera. In J. Eder and H. Rembold, ed. Chemistry and Biology of Social Insects. (Tenth International Congress of the International Union for the Study of Social Insects, August 1986), pp. 81-84, J. Peperny, Munich.

BLUM, M.S. 1982. Pheromonal bases of insect sociality: communications, conundrums and caveats. Les Mediateurs Chimiques (Les Colloques de l'INRA, Versailles, 1981). 7: 149-162.

Bhatkar, A. AND W. H. Whitcomb. 1970. Artificial diet for rearing various species of ants. Fla. Entomologist 53: 229-232.

Buschinger, A. And U. Maschwitz. 1984. Defensive behavior and defensive mechanisms in ants. In H. R. Hermann, ed., Defensive mechanisms in social insects, pp. 95-150. Praeger, New York. 
HölLDOBLER, B., 1978. Ethological aspects of chemical communication in ants. Advances in the Study of Behavior, 8: 75-115.

HöllDoBler, B. 1982. Chemical communication in ants: new exocrine glands and their behavioral function. In M. D. Breed, C. D. Michener, and H. E. Evans, ed., The biology of social insects. (Proceedings of the Ninth Congress of the International Union for the Study of Social Insects, Boulder, Colorado, August 1982) pp. 312-317. Westview Press, Boulder.

HöllDOBLER, B. 1984. Evolution of insect communication. In T. Lewis, ed. Insect Communication (Twelfth Symposium of the Royal Entomological Society, London) pp. 349-377. Academic Press, London.

Hölldobler, B. AND H. Engel. 1978. Tergal and sternal glands in ants. Psyche, 85: $285-330$.

Jessen, K. U., U. Maschwitz, and M. Hahn. 1979. Neue Abdominaldrüsen bei Ameisen. I: Ponerini (Formicidae: Ponerinae). Zoomorphologie, 94: 49-66.

Morgan, E. D. 1984. Chemical words and phrases in the language of pheromones for foraging and recruitment. In T. Lewis, ed., Insect communication (Twelfth Symposium of the Royal Entomological Society, London), pp. 169-194. Academic Press, London. 

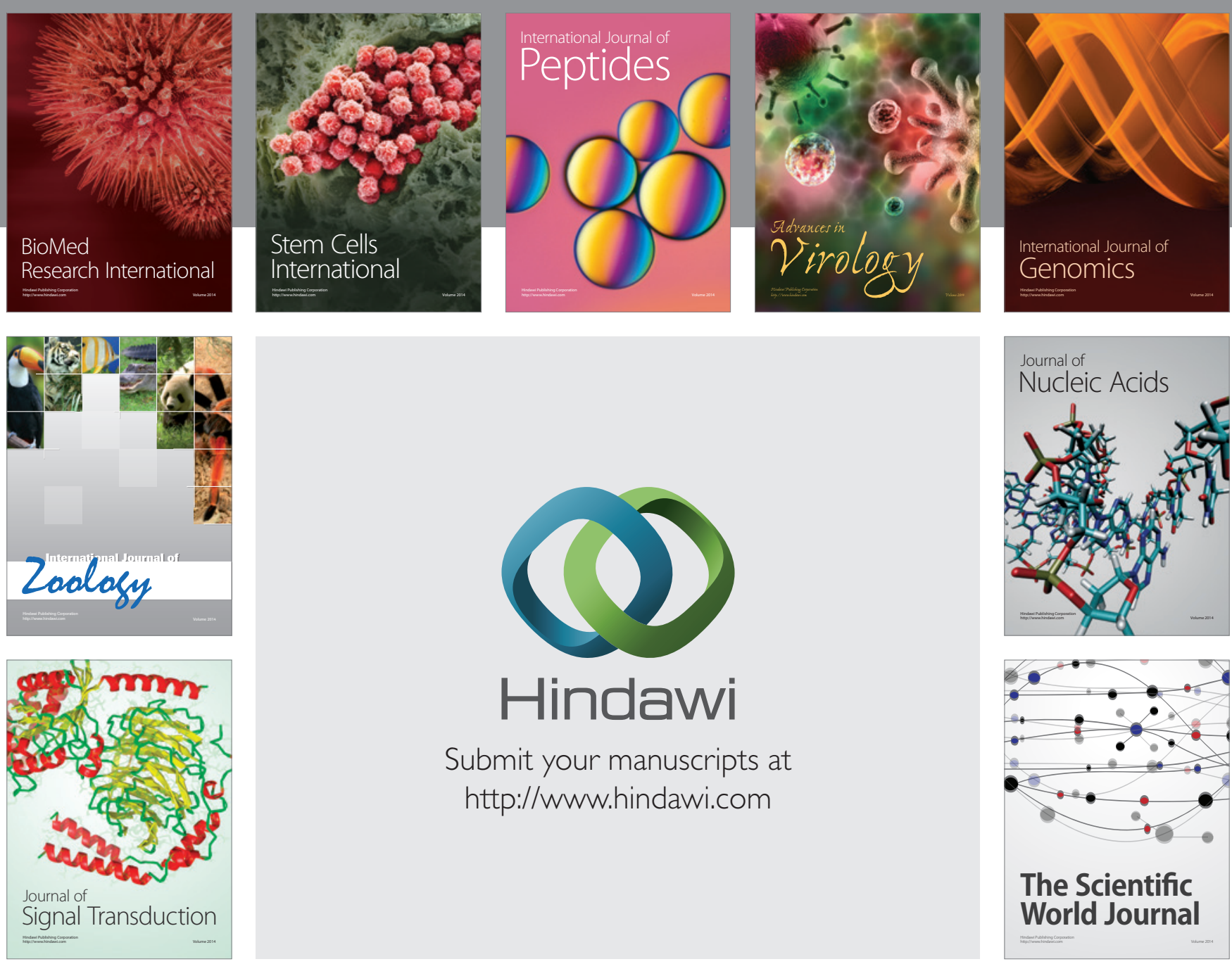

Submit your manuscripts at

http://www.hindawi.com
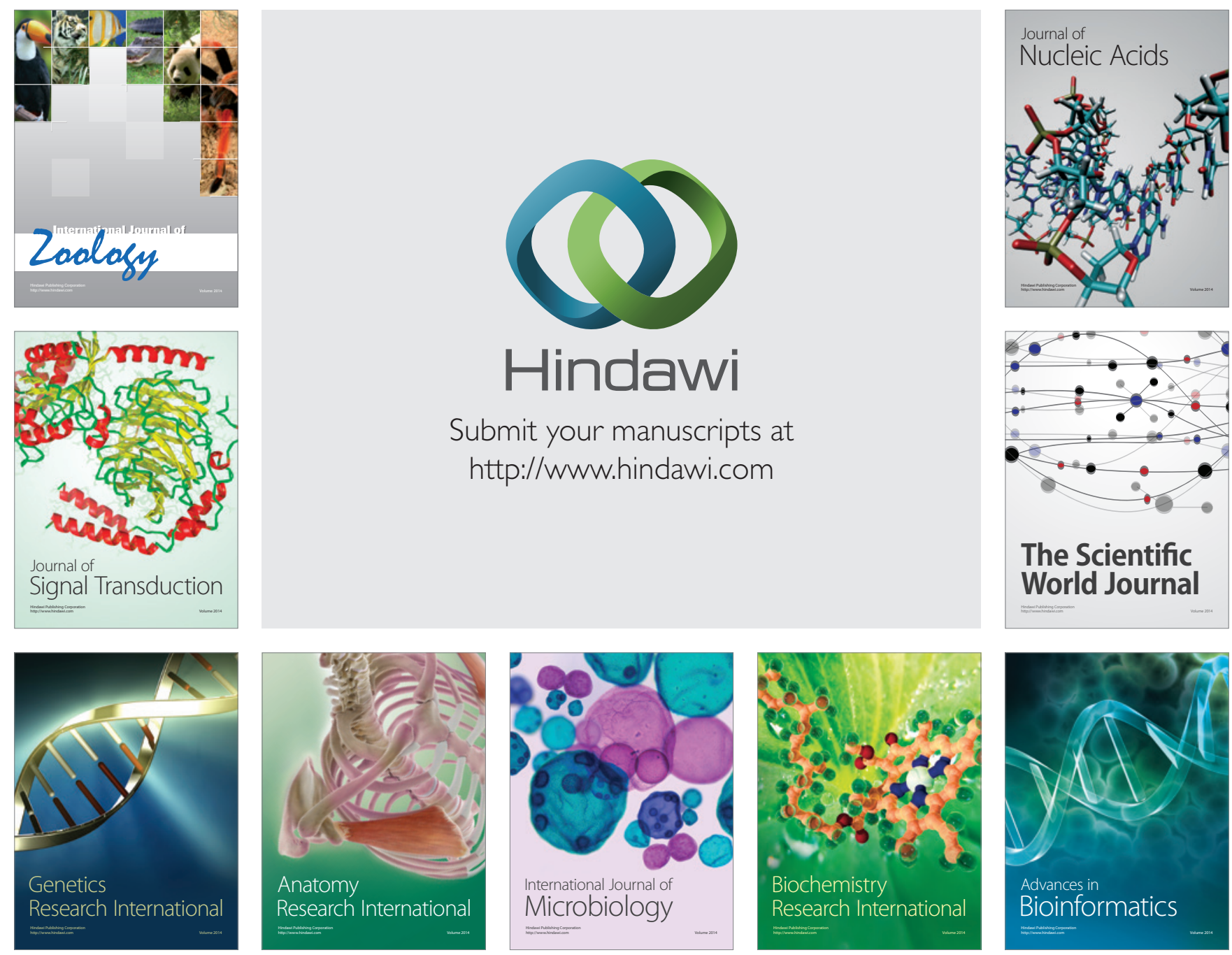

The Scientific World Journal
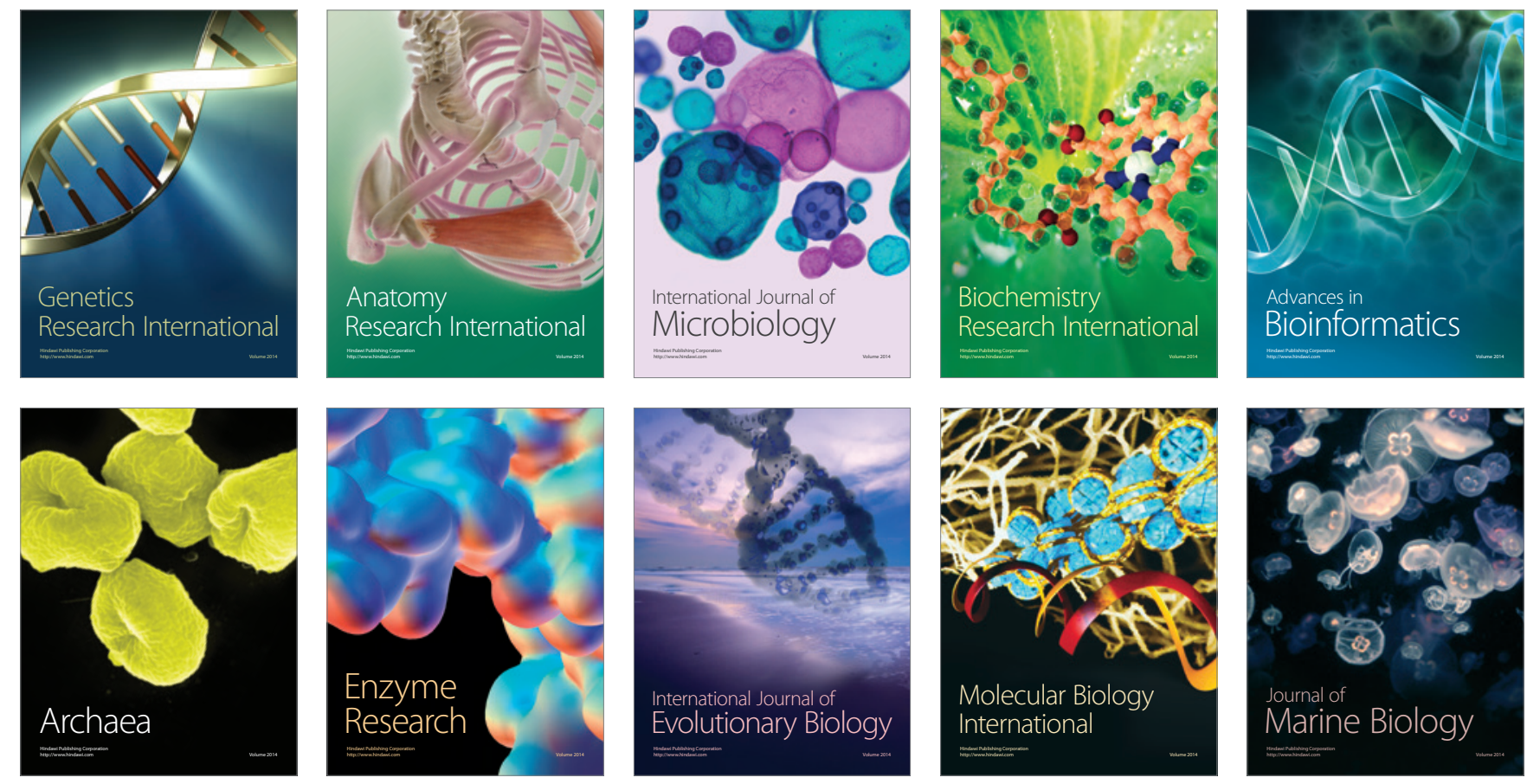